\title{
POBREZA RURAL EN LA PROVINCIA DEL CHACO. UN ANÁLISIS A PARTIR DEL INDICE DE PRIVACIÓN MATERIAL DE LOS HOGARES (IPMH)
}

\author{
Alejandra H. Torre Geraldi \\ ageraldi@bib.unne.edu.ar \\ Instituto de Geografía- UNNE
}

\section{Resumen}

La provincia del Chaco, en el transcurso de la década del '90, ha manifestado el empobrecimiento del sector agrario como consecuencia de los vaivenes que presentó la economía del país en el transcurso del período en estudio. Este proceso de decadencia impactó directa y especialmente, en el segmento social correspondiente a los pequeños productores cuya base económica se sustentó, desde siempre, en el trabajo familiar.

Ante esta situación, se pretende, dentro del marco de la Geografía Humana, identificar las características socioeconómicas de la población rural en la provincia del Chaco, analizando los factores que incidieron en el aumento de la pobreza rural y caracterizar el comportamiento de los niveles de pobreza rural en el espacio provincial durante la década del 1990

Palabras claves: pobreza rural, población rural, pequeño productor, economía familiar

\section{Abstract}

The province of the Chaco, in the course of the decade of 90, has demonstrated the impoverishment of the agrarian sector as consequence of the sways that presented the economy of the country in the course of the period in study. This process of decadence affected directy, and specially, the social segment corresponding to the small producers whose economic base was sustained, from always, the familiar work.

Before this situation, one tries, inside the frame of the Human Geography, to identify the socioeconomic characteristics of the rural population in the province of the Chaco, analyzing the factors that affected in the increase of the rural poverty and to characterize the behavior of the levels of rural poverty in the provincial space during the decade of 90

Key words: Rural poverty, rural population, small producer, familiar(family) economy 


\section{Introducción}

En el transcurso de la década del 90 se generaron, en la República Argentina, profundas transformaciones a nivel económico, político y social. La apertura unilateral de la economía, el ajuste fiscal, la retracción de los mecanismos de regulación e intervención del Estado, la privatización de las empresas de servicios públicos y la convertibilidad peso/dólar, fijaron un nuevo escenario para las políticas, redefinieron los interlocutores privilegiados del Estado en el proceso de toma de decisiones y condicionaron profundas transformaciones en la estructura socioeconómica del país. (Lattuada y Neiman, 2005: 9)

Estos cambios han impactado directamente en el sector rural y especialmente agropecuario del país a partir de la desfragmentación y en la mayoría de los casos desaparición de organismos e instituciones que regulaban esta actividad. Sin embargo la actividad agraria se intensificó en volúmenes de producción y exportaciones a partir de la modernización de los mecanismos de labranza. Esta coyuntura derivó en un vertiginoso proceso de concentración de tierras y exclusión de los menos favorecidos dentro del sistema productivo Nacional, regional y provincial.

Teniendo en cuenta el panorama rural provincial, el Chaco ha manifestado el empobrecimiento acelerado del sector agrario, debilitado por décadas, en correlato con los vaivenes que presentó la economía del país en el transcurso de este período. Este proceso de decadencia impactó directa y especialmente en el segmento social correspondiente a los pequeños productores cuya base económica se sustentó, desde siempre, en el trabajo familiar.

Ante esta situación, exacerbada durante la última década del siglo XX se pretende, dentro del marco de la Geografía Humana, identificar las características socioeconómicas de la población rural en la provincia del Chaco, analizando los factores que incidieron en el aumento de la pobreza rural en ese espacio y caracterizar el comportamiento de los niveles de pobreza rural a nivel provincial durante la década del 90.

\section{La pobreza rural en la provincia del Chaco: Causas generales}

La situación de pobreza en el ámbito rural chaqueño a fines de la década del 90 es el reflejo de la crisis económica a nivel nacional producida en el transcurso de ese período. Si se toma como referencia los factores negativos que propiciaron el avance de la pobreza en la provincia, se puede hacer referencia a la crisis algodonera de las últimas décadas afectada por catástrofes hídricas y sequías, los cambios en las cotizaciones y el reemplazo de la fibra natural. Otras causas fueron la desaparición de minifundios a partir del proceso de concentración de tierras adquiridas por "megaproductores"; el surgimiento de nuevas tecnologías que acompañaron a la expansión de la soja, difíciles de ser incorporadas por las pequeñas o medianas explotaciones con productores descapitalizados; el desplazamiento de la producción pecuaria con la expansión sojera; la reducción de mano de obra asalariada, entre otras. Lattuada y Neiman (2005) señalan que cualesquiera de estas circunstancias, por demás frecuentes en el sector agropecuario, afectaban el ingreso final de las explotaciones y reducían su propia capacidad y posibilidad de reinicio del ciclo productivo, viéndose obligadas a caer en un sistema de endeudamiento creciente. Estas causas constituyeron un denominador común en los discursos de los agricultores -como se mencionó inicialmente- endeudados con situación irregular de cumplimiento, transformando una herramienta tradicionalmente considerada de crecimiento, como es la disponibilidad de crédito, en un factor de empobrecimiento y expulsión del medio rural.

\section{Principales factores que incidieron en el aumento de la pobreza rural a nivel provincial durante la década del $\mathbf{9 0 .}$}

Se debe señalar que en la provincia existe un predominio de productores minifundistas (explotaciones inferiores a 100 has.) que han sido, en las últimas décadas, los principales

Publicado en formato digital: Prof. Alejandra H. Torre Geraldi. POBREZA RURAL EN LA PROVINCIA DEL CHACO. UN ANÁLISIS A PARTIR DEL INDICE DE PRIVACIÓN MATERIAL DE LOS HOGARES (IPMH). Revista Geográfica Digital. IGUNNE. Facultad de Humanidades. UNNE. Año 9. No 17. Enero - Junio 2012. ISSN 16685180 Resistencia, Chaco. En: http://hum.unne.edu.ar/revistas/geoweb/default.htm 
afectados por el avance de la pobreza dado que se han manifestado una serie de condicionantes que pusieron en jaque la economía de los pequeños productores (1). La imposibilidad de ingresar a procesos más o menos sostenidos de capitalización determinando una orientación de las unidades hacia estrategias de subsistencia definidas en torno a un objetivo económico de maximización de un ingreso total. El agregado de otros condicionantes tales como los inadecuados canales de comercialización, la baja diversificación productiva, la subocupación, entre otros, completa un cuadro de limitaciones económicas y sociales, que explica y refuerza la condición de pobreza en estas unidades (Neiman, 1997). Asimismo, han deteriorado su nivel socioeconómico debido a los sucesivos factores ambientales y técnico -productivos propios de las últimas décadas del siglo XX.

\section{A- La crisis algodonera chaqueña}

Luego de una etapa beneficiada por los buenos precios internacionales, a mediados de la década del 70 , se genera la crisis algodonera a partir de la combinación de diferentes factores, pudiéndose destacar el desvanecimiento de los precios internacionales, junto con los peores embates que ha sufrido la industria textil, por lo tanto existe un abandono de las chacras por parte de los pequeños y medianos productores descapitalizados y endeudados, prolongándose esta situación hasta 1982/83 (2). A esto se debe sumar a esto los daños producidos por efecto de la inundación, como señala Valenzuela (2000) el algodón es un cultivo de secano cuya permanencia depende de condiciones meteorológicas "normales", las cuales no siempre se dan ya que uno de los rasgos ecológicos sobresalientes de la zona es la alta variabilidad pluviométrica.

En la campaña 1985/86 se produce la primera mínima histórica con la disminución de la superficie sembrada alcanzando 150.000 has, originada principalmente por la oscilación de los precios.

Durante el período 1991/92 los excesos hídricos volvieron a afectar el espacio algodonero determinando la reducción del área sembrada. A su vez la caída de los precios internos del textil estaba fuertemente ligada a los precios del mercado externo. En esta etapa se produce una fuerte disminución de la demanda de la fibra a partir de su sustitución por fibras sintéticas.

A partir de la campaña 1995/96 el algodón dio un respiro a los productores y minifundistas ya que se genera el "boom" algodonero, ocupando aproximadamente el $60 \%$ de la superficie cultivable."Fue una cosecha con rindes máximos históricos y precios por las nubes de la fibra que conjugan un cóctel fantástico que infundió un aliviador Shock de rentabilidad a este sector productivo recurrentemente mal tratado por el clima y los mercados" (3).

Hacia 1998/99 el algodón vuelve a ser protagonista de una nueva crisis determinada por los problemas climáticos generadores de excesos hídricos que provocó una baja en la productividad (4), pérdida en la calidad de la fibra y una fuerte caída del precio internacional.

En la campaña 2001/02 el conflicto algodonero estuvo afectado por las sombrías perspectivas económicas generales y una situación internacional incierta son los factores que continúan gravitando pesadamente sobre el mercado (5). Sin embargo la mínima histórica se manifiesta en el período 2002/003 con menos de 100.000 has implantadas representando aproximadamente un $10 \%$ de la superficie agrícola. Las causas están originadas por factores climáticos y económicos. "El clima de los últimos cuatro años, con la helada histórica más temprana, intensa sequía y otoños excesivamente húmedos determinó que los rendimientos promedios (a pesar de la aplicación de nuevas tecnologías) estuviesen por debajo del promedio histórico. La disminución de los valores internacionales de la fibra de algodón durante un período tan prolongado hasta niveles que hacen que la producción sin subsidios estatales sea difícil de sostener para sistemas de producción intensivos de cualquier país. esta disminución del área sembrada se ve agravada por la aparición de una alternativa de gran importancia, el cultivo de soja RR en siembra directa, cultivo este que requiere una inversión sensiblemente inferior, menos estructura, y se obtiene una mayor

Publicado en formato digital: Prof. Alejandra H. Torre Geraldi. POBREZA RURAL EN LA PROVINCIA DEL CHACO. UN ANÁLISIS A PARTIR DEL INDICE DE PRIVACIÓN MATERIAL DE LOS HOGARES (IPMH). Revista Geográfica Digital. IGUNNE. Facultad de Humanidades. UNNE. Año 9. № 17. Enero - Junio 2012. ISSN 16685180 Resistencia, Chaco. En: http://hum.unne.edu.ar/revistas/geoweb/default.htm 
renta por peso invertido, razones que agravadas por la falta de financiamiento y de recursos propios hacen difícil la decisión de siembra de algodón"(6).

El sistema minifundista ha tenido por décadas el desarrollo del cultivo algodonero como base económica familiar, sin embargo a partir de la década del '80 este cultivo ha manifestado crisis cíclicas que ha llevado al pequeño productor agropecuario a cambiar drásticamente su situación socioeconómica.

\section{B- Adquisición y concentración de tierras}

El precio de las tierras en la República Argentina posee un valor inferior a la de otros países con características ecológicas similares. La tierra argentina vale $30 \%$ menos que la australiana y $50 \%$ menos que la norteamericana, y la rentabilidad promedio es varias veces más alta.(7)

Las inversiones realizadas en nuestro país son de origen local (en calidad de megaempresas) e internacionales. Según Ambrosetti (1998:30) esta ola de inversiones que vive el campo también impulsa un proceso de concentración en la tenencia de la tierra. Se trata de una tendencia que ya se afianzó en la mayoría de los países desarrollados y parece inevitable en la medida en que se presenta como la única forma que tienen los productores argentinos de trabajar en escala y reducir sus costos para poder competir en los mercados internacionales". Por otra parte, Zorraquín (1998:30) señala "que la concentración va a seguir por un problema de escala, si se trabaja con pequeños campos, se sale hecho o se corre el riesgo de perder plata. Una familia para vivir bien necesita, por lo menos 700 hectáreas y una empresa 5000" esta situación es visiblemente observable en el norte argentino, especialmente en la provincia del Chaco, donde existe una variación de las Explotaciones Agropecuarias entre los censos 1988 y 2002, cuyos departamentos han presentado el incremento de EAPs que superan las 1000 hectáreas generado por la adquisición y concentración de tierras por parte de los grandes productores, Este proceso ha determinado que el $60,9 \%$ de los departamentos de dicha provincia hayan perdido un número importante de pequeñas y medianas explotaciones pertenecientes a aquellos productores familiares que no han logrado sostener en el tiempo una estabilidad económicaproductiva. Este grupo poblacional ha sido expulsado del sector hacia los centros urbanos en busca de nuevas posibilidades de trabajo; los mismos se han localizado en las áreas periféricas de la ciudad sin haber alcanzado cierto grado de sustentabilidad económicalaboral. (8)

\section{C- Variación en el tipo de tenencia de la tierra}

El sistema de adquisición de tierras más utilizado además de la compra es el alquiler, Zorraquín (1998:32) afirma lo que se paga en concepto de alquiler es menos que los gastos fijos que ocasiona ser dueño de un campo, además otorga la flexibilidad para salir (en muchas ocasiones cuando se alcanza el agotamiento total de los suelos), entrar, crecer o achicarse cuando se quiere.

Esta misma tendencia presentan los departamentos de la provincia; sin embargo, al observar el Mapa № 1 (9) - discriminado por radios censales- se puede advertir para el Censo 2001 un bajo porcentaje de población propietaria de tierras rurales, alcanzando los máximos valores en la franja centro de la provincia en donde se ha desarrollado por décadas el cultivo algodonero. Hacia el este las tendencias disminuyen predominando montos relativos que no superan el 25\%; pudiéndose observar, en forma particular al departamento Tapenagá donde sólo el $12 \%$ de los ocupantes poseen título de propiedad.

La situación relativa en el oeste provincial adquiere un carácter aun más heterogéneo. En los radios correspondientes a los departamentos del sudoeste provincial predominan entre un 50 y $74,9 \%$ de propietarios, al igual que en algunos radios de los departamentos Almirante Brown y Gral. Güemes, la presencia de esta situación puede estar vinculada con

Publicado en formato digital: Prof. Alejandra H. Torre Geraldi. POBREZA RURAL EN LA PROVINCIA DEL CHACO. UN ANÁLISIS A PARTIR DEL INDICE DE PRIVACIÓN MATERIAL DE LOS HOGARES (IPMH). Revista Geográfica Digital. IGUNNE. Facultad de Humanidades. UNNE. Año 9. No 17. Enero - Junio 2012. ISSN 16685180 Resistencia, Chaco. En: http://hum.unne.edu.ar/revistas/geoweb/default.htm 
la expansión de la frontera agropecuaria a partir de la inserción del cultivo de soja acompañada por la adquisición de tierras por los grandes productores extrarregionales.

Mapa $N^{\circ} 1$

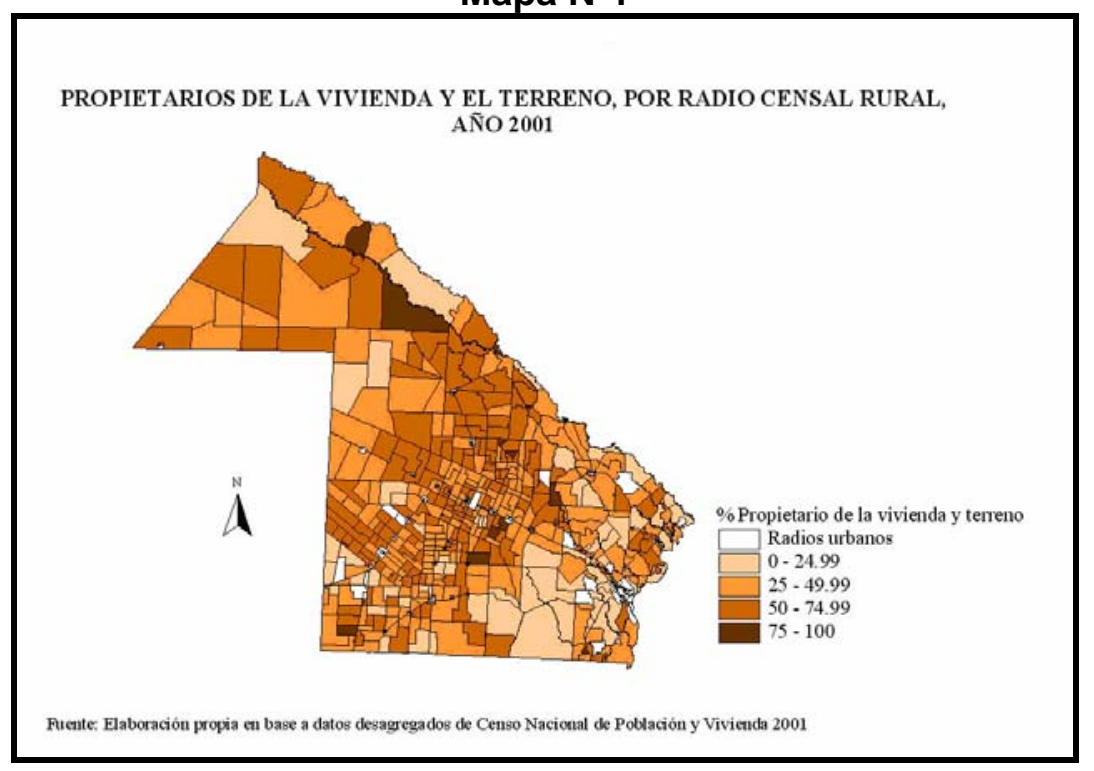

\section{D- Incorporación de Paquetes tecnológicos para el cultivo de soja}

La evolución de la soja en el sistema de producción nacional y provincial ha ido acompañada con la incorporación de nuevas tecnologías las cuales conforman un paquete integrado por insumos, maquinarias y semillas modificadas genéticamente. La aplicación de paquetes tecnológicos permite en tiempos y espacios reducidos obtener óptimos resultados, intensificando la labor del suelo y ahorrando mano de obra a partir de la mecanización masiva de esta actividad.

Este sistema de laboreo ha diseñado un nuevo panorama en el sistema socioeconómico rural chaqueño Los nuevos paquetes tecnológicos que integraron siembra directa con maquinaria importada, herbicidas y sojas transgénicas, instalaron una agricultura sin agricultores. La extendida e intrincada red de contratistas de maquinaria agrícola y de distribuidoras locales de insumos, así como la vida cultural y social que acompañaba a la pequeña agroindustria y a los pueblos rurales, desaparecieron dejando inmensos territorios vacíos.(10)

\section{El Índice de Privación Material de los Hogares (IPMH)}

\section{A- Privación de Recursos Corrientes (PR)}

Si se considera la Privación de Recursos Corrientes'(11), se puede distinguir (Mapa $\mathrm{N}^{\circ} 2$ ) que las tres cuartas partes de los radios que constituyen a la provincia del Chaco poseen menos del $6 \%$ de hogares con esta privación; y sólo una minoría, localizada en el sudoeste y este provincial superan el $22 \%$. Estos últimos están asociados con una pobreza de tipo coyuntural y probablemente se relaciona con los bajos ingresos de la población, la baja asistencia escolar, las fluctuaciones del mercado laboral y la informalidad del empleo rural.

También se observa que el $80 \%$ de los radios correspondientes a los departamentos del oeste chaqueño (Almirante Brown y General Güemes), no poseen "exclusivamente" este tipo de privación. 


\section{Mapa $\mathrm{N}^{\circ} 2$}

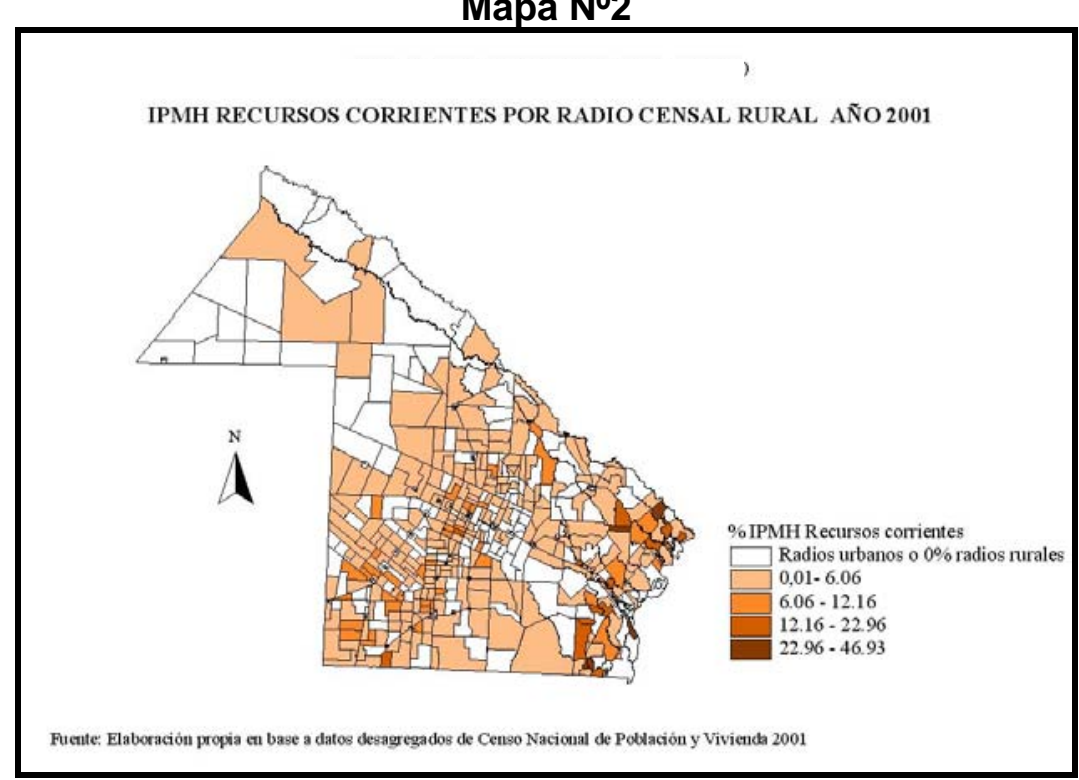

\section{B-Privación de Recursos Patrimoniales (PP)}

Si se considera que a partir del cálculo del índice CONDHAB (12) y de la definición de un umbral de carencia se determinan aquellos hogares con "Privación de Recursos Patrimoniales" asociado a la condición de pobreza estructural, se puede reconocer que esta privación -según los datos representados- es relevante en prácticamente el $90 \%$ del total de los radios rurales de la provincia (Mapa $N^{\circ} 3$ ). Esta situación se encuentra asociada con el déficit estructural de las viviendas, la ausencia de agua por red y de infraestructuras sanitarias. Esas viviendas se adaptan a las condiciones climáticas de la zona, pero los materiales con los cuáles se construyen son nocivos para la salud y para el bienestar general (13).

\section{Mapa $N^{\circ} 3$}

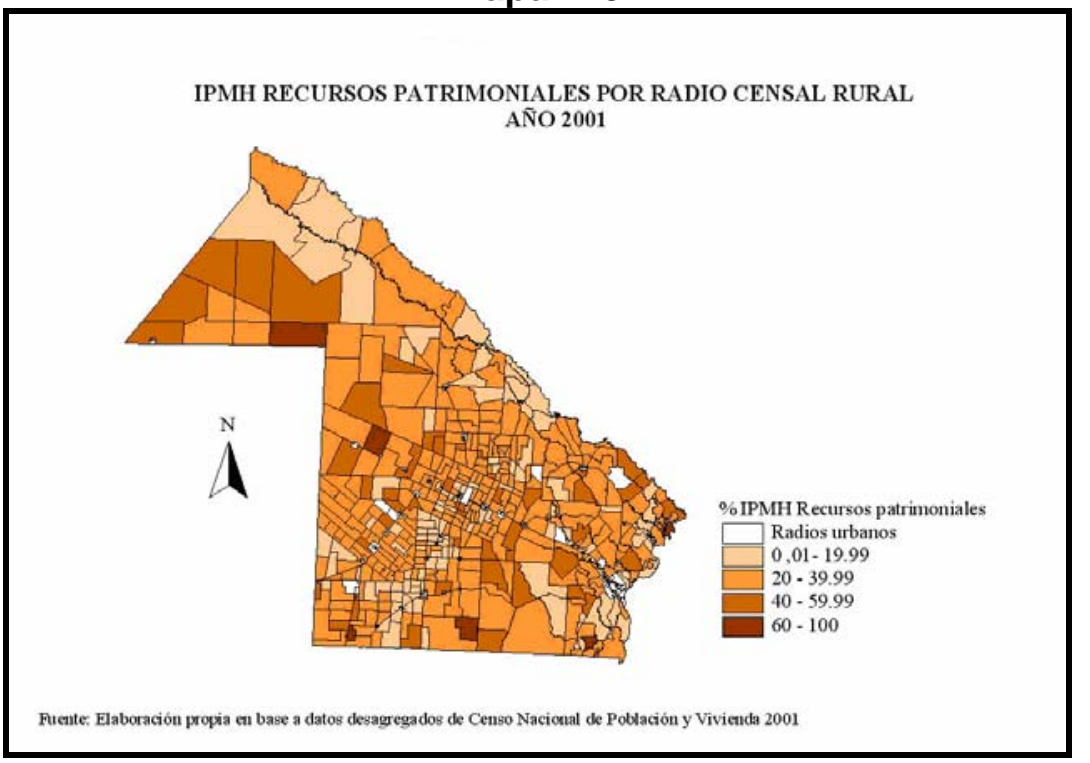

Publicado en formato digital: Prof. Alejandra H. Torre Geraldi. POBREZA RURAL EN LA PROVINCIA DEL CHACO. UN ANÁLISIS A PARTIR DEL INDICE DE PRIVACIÓN MATERIAL DE LOS HOGARES (IPMH). Revista Geográfica Digital. IGUNNE. Facultad de Humanidades. UNNE. Año 9. № 17. Enero - Junio 2012. ISSN 16685180 Resistencia, Chaco. En: http://hum.unne.edu.ar/revistas/geoweb/default.htm 


\section{C-Privación de Recursos Convergentes (PC)}

Luego de identificar aquellos radios que manifiestan sólo un tipo de privación- ya sea corriente o patrimonial- se representaron los que poseen conjuntamente ambos tipos de privaciones, conformando el subgrupo de Privación de Recursos Convergentes.

En la representación cartográfica (Mapa $\mathrm{N}^{\circ} 4$ ) se evidencia que la totalidad de los radios censales de la provincia del Chaco (excepto uno, correspondiente al departamento Tapenagá) presentan ambos tipos de privaciones alcanzando los máximos porcentajes en el norte y centro provincial correspondiente al ámbito más pobre del Chaco. En el norte, se reconoce especialmente el elevado porcentaje de población nativa con deficiencias habitacionales, carencia de instrucción formal y alto nivel de desocupación. El sector central, coincide con la presencia de pequeños productores que subsisten mediante el trabajo familiar, poseen un nivel de instrucción restringido y conviven en infraestructura habitacional deficitaria

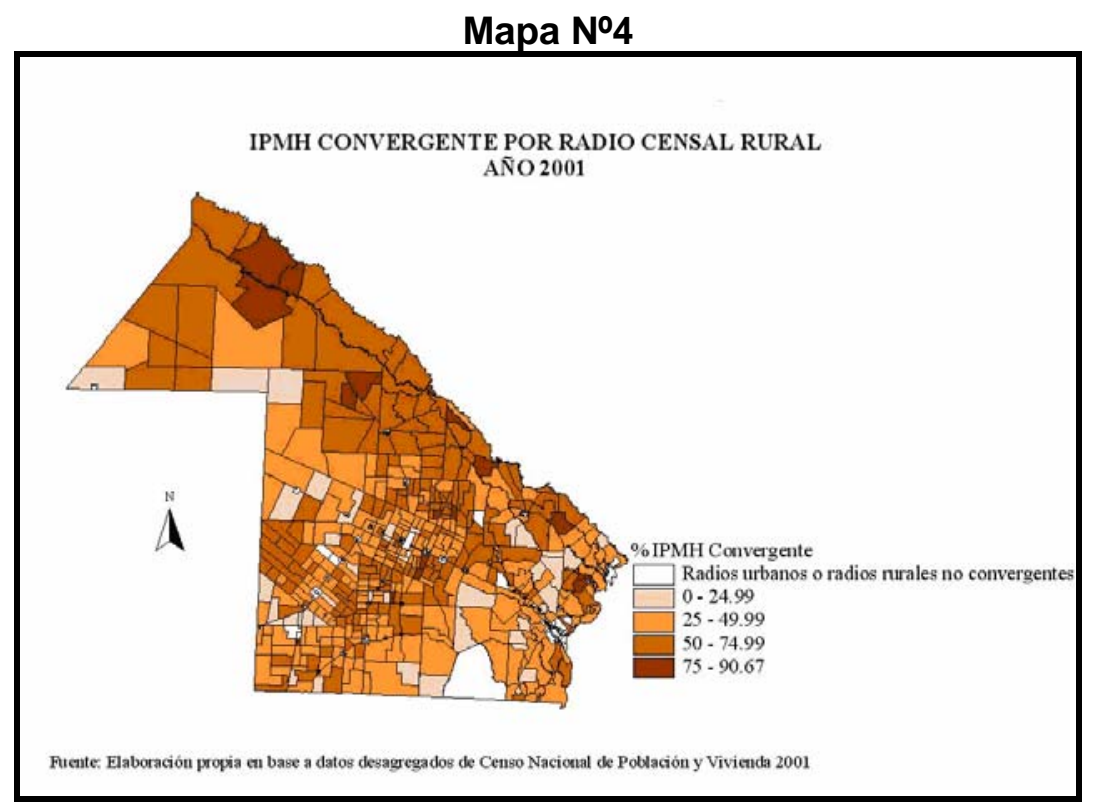

\section{Niveles de pobreza rural en la Provincia de Chaco}

La utilización complementaria de medidas derivadas del IPMH(14) permite medir la Intensidad de la pobreza. Como lo indica Gómez (2003), constituyen herramientas cualitativamente diferentes de las tradicionales para el abordaje de la pobreza a partir de datos censales que posibilitan una descripción más detallada de la realidad y permite, a la vez, una aproximación válida para el diseño y aplicación de políticas en distintos ámbitos de la acción social y localización territorial(15).

Para evaluar la pobreza en la provincia del Chaco se trabajó a nivel de radios y se definieron cinco Niveles de Intensidad de la Pobreza de acuerdo al IPMH (16). Con el fin de reconocer espacialmente cuáles son las áreas que presentan mayores privaciones. La unidad de análisis del trabajo fue el hogar, por ser la unidad estadística colectiva significativa.

A través de la Intensidad de IPMH, se busca resaltar el porcentaje de los hogares con privación convergente $(\mathrm{PC})$ con respecto al total de hogares con algún tipo de privación, ya sea de recursos corrientes (PR), patrimonial (PP) o inclusive privación convergente.

$$
I P M H \text { Intensidad }=\quad \frac{P C}{P R C+P P+P C}
$$


Entonces, con este indicador se pueden reconocer los espacios donde la pobreza muestra la combinación de ambos tipo de privaciones: la estructural y la coyuntural.

\section{Mapa $N^{\circ} 5$}

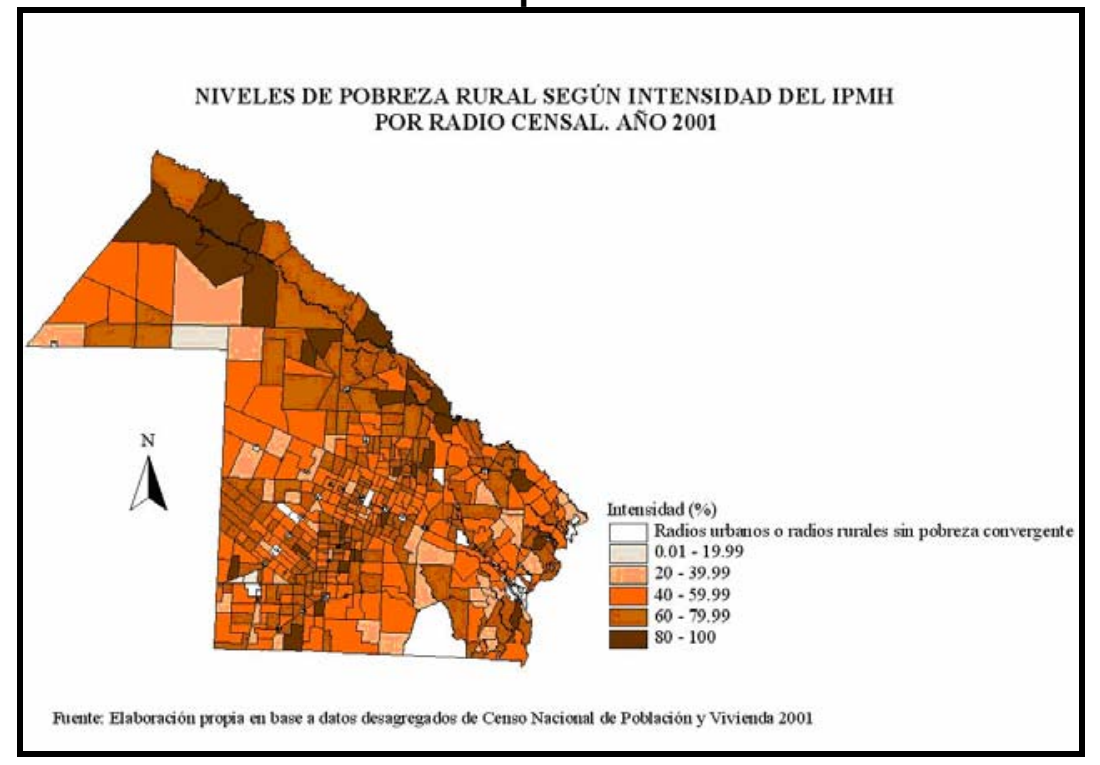

Los datos correspondientes a la Intensidad de la pobreza, muestran que prácticamente la totalidad de los radios censales rurales tienen más del $40 \%$ de hogares con algún tipo de privación (Mapa $N^{\circ} 5$ ). La situación es más fuerte en el norte y a lo largo de la diagonal que atraviesa el centro de la provincia, donde la intensidad es superior al 60\%. Esta escenario se justifica por los mismos motivos explicitados en el punto anterior: la presencia de población nativa y productores empobrecidos por la nueva coyuntura económica del país, ambos grupos, por situaciones disímiles, se encuentran sumidos en un elevado nivel de pobreza.

\section{Consideraciones Finales}

Los efectos de las políticas económicas implementadas en Argentina -durante las últimas tres décadas y especialmente a fines del siglo $\mathrm{XX}$-, han repercutido intensamente en el universo rural chaqueño

En el Chaco, el sector agropecuario ha sostenido económicamente a la provincia durante décadas, sin embargo la coyuntura económica de la década del '90 ha desdibujado su estructura de origen. Golpeados inicialmente con las sucesivas crisis del algodón, los minifundistas y medianos productores se encontraron a fines de siglo con un nuevo panorama productivo que los ha aislado o directamente excluido del relativo "circuito comercial en que se manejaban".

En los últimos años el sector pecuario y algodonero fue desplazado por la actividad agraria intensiva, específicamente con la incorporación del cultivo masivo de soja especialmente en el oeste y sudoeste provincial. A partir de este proceso de inserción se incorporaron nuevas métodos de producción que desplazaron la mano de obra humana o simplemente la esta tecnología no ha podido ser asimilada por los pequeños productores.

Este moderno sistema productivo ha fortalecido el deterioro de los ingresos, asimismo, se incrementó la informalidad del empleo a partir del trabajo en negro; aumentó la subocupación y desocupación en forma vertiginosa generando el endeudamiento irreversible de los menos beneficiados en este sistema. Estos condicionantes sumaron al núcleo 
tradicional de la pobreza a un conjunto de hogares que, hasta entonces, no podrían haberse considerado como pobres.

Para el estudio de la pobreza en el Chaco se empleó la metodología del IPMH que, aunque está construida para el estudio de la pobreza en áreas urbanas, igualmente ha podido ser aplicado al ámbito rural.

Este indicador más ajustado a la realidad, posibilitó el reconocimiento del espacio más pobre del sector rural, constituido por una "c invertida" que abarca desde el noroeste provincial y hacia el centro y sur del Chaco donde se localizan las comunidades nativas en el primer caso, y los antiguos productores algodoneros en el segundo espacio. Ambos grupos, por causas diferentes conviven, en la actualidad, en condiciones análogas de pobreza.

Este sistema de medición, poco habitual para el estudio de la pobreza rural, ha permitido una aproximación más exacta sobre el reconocimiento de la pobreza en este ámbito, dándole un carácter novedoso al trabajo y permitiendo brindar una visión sintética de esta realidad representada a fines de la última década del siglo XX. 
Revista Geográfica Digital. IGUNNE. Facultad de Humanidades. UNNE. Año 9. No 17. Enero - Junio 2012. ISSN 1668-5180 Resistencia, Chaco

\section{Notas}

(1)Las explotaciones agropecuarias de pequeños productores son aquellas en las que el productor o socio trabaja directamente en la explotación y no emplea trabajadores no familiares remunerados permanentes (Obschatko, 2006)

(2) Besil, A. 2002 P: 5

(3) "Historia de un productor algodonero al que siempre le fueron bien las cosas". Suplemento Norte Rural. En: Diario Norte. 06/09/2000:7

(4)Las estimaciones generales de los daños ocasionados por las inundaciones ocurridas entre septiembre de 1997 y abril de 1998 arrojaron para el Chaco la pérdida de 644.205 toneladas de la producción agrícola, en 376.550 hectáreas afectadas, siendo los pequeños y medianos productores los más agobiados por el endeudamiento derivado de los pagos pautados a cosecha futura. Valenzuela de Mari. 2000:155

(5)“El precio internacional del algodón no detiene su caída" Suplemento Norte Rural. En Diario Norte. 07/11/2001: 4.

(6)Donelly, Lorenzo. "La rentabilidad del algodón según el perfil del productor" Suplemento Norte Rural. En: Diario Norte.02/01/2003: 4.

(7)“El capitalismo llegó al campo”. En Revista Mercado. 1998: 22

(8)Señala Valenzuela (2006:136) "Las tendencias generales profundizaron la concentración del usufructo de la tierra productiva, el desplazamiento de pequeños y medianos productores ante la elevación de la escala económica y las exigencias de capital requeridas para dedicarse a la agricultura, con lo que se aceleró el proceso de diferenciación de la estructura agraria y la expulsión de los productores que no alcanzaron la escala mínima exigida en cada caso."

(9)En el Mapa $N^{0} 1$ se representa el porcentaje de propietarios teniendo en cuenta la sumatoria de población rural agrupada y dispersa según radios censales

(10)La biotecnología y el modelo rural en los orígenes de la catástrofe que arrasa a la Argentina".Grupo de Reflexión Rural. En Internet: http://www32.brinkster.com

(11)La Privación de Recursos Corrientes surge del Índice CAPECO. Este indicador se construye a partir de la relación entre los años de educación formal aprobados por los perceptores de ingresos y la cantidad total de miembros del hogar (Alvarez, 2002).

(12)El indicador está construido a partir de las características de los materiales constructivos y de la infraestructura sanitaria que componen la vivienda (Álvarez, 2002, Gómez, 2003, Silva 2003).

(13Los tipos de viviendas predominantes son los ranchos compuestos por techos de paja o barro con paja, combinados fundamentalmente con paredes de adobe 0 de piedras y pisos de tierra.

(14)Como este indicador no puede ser homologado con el objeto de aplicarlo a los registros del censo nacional de 1991, no se puede realizar ninguna comparación intercensal, a los efectos de reconocer variaciones temporales del fenómeno de pobreza rural.

(15)La nueva metodología aquí presentada constituye un instrumento de medición con alto poder discriminatorio que reproduce diferentes alternativas de satisfacción de necesidades básicas, distinguiendo grupos internamente homogéneos y diferentes entre sí. EI IPMH permite distinguir entre las diferentes situaciones de privación que afectan a los hogares según el tipo y la intensidad, ofreciendo una aproximación a la pobreza que va más allá de

Publicado en formato digital: Prof. Alejandra $\mathrm{H}$. Torre Geraldi. POBREZA RURAL EN LA PROVINCIA DEL CHACO. UN ANÁLISIS A PARTIR DEL INDICE DE PRIVACIÓN MATERIAL DE LOS HOGARES (IPMH). Revista Geográfica Digital. IGUNNE. Facultad de Humanidades. UNNE. Año 9. № 17. Enero - Junio 2012. ISSN 16685180 Resistencia, Chaco. En: http://hum.unne.edu.ar/revistas/geoweb/default.htm 
la dicotomía entre pobres y no pobres, dando cuenta de la heterogeneidad de la misma (Gómez y otros, 2003).

(16)Los cinco niveles de intensidad que se establecieron, fueron: Nivel I. 0,01 a 19.99\%; Nivel 2. 20 a 39.99\%; Nivel 3. 40 a 59.99\%; Nivel 4. 60 a 79.99\%; Nivel 5: 80 a 100\% 
Revista Geográfica Digital. IGUNNE. Facultad de Humanidades. UNNE. Año 9. № 17. Enero - Junio 2012. ISSN 1668-5180 Resistencia, Chaco

\section{Referencias Bibliográficas}

ÁLVAREZ, Gustavo. Capacidad económica de los hogares. Una aproximación a la insuficiencia de ingresos. En Notas de Población N074.. CEPAL. Santiago de Chile. 2002: 213-250.

BANCO INTERAMERICANO DE DESARROLLO, Dpto. de Desarrollo Sostenible, División de Medio Ambiente. Estrategia para la reducción de la pobreza rural. Washington, D.C.1998

BESIL, Antonio. El cultivo del algodón en el Chaco en la década de los noventa. XXII Encuentro de Geohistoria Regional. 4 y 5 /10. Resistencia, Chaco. 2002. Versión CDRom

GALPERIN, Hernan. Políticas TICs y Pobreza: El Caso Argentino. Universidad de San Andrés (Argentina)/University of Southern California, 2004. http://www-rcf.usc.edu/

GÓMEZ, A. SILVIA, M. OLMOS, F. Índice de Privación Material de los Hogares (IPMH). Desarrollo y aplicación con datos del Censo Nacional de Población y Viviendas 2001 En: VII Jornadas Argentinas de Estudios de Población (AEPA). Universidad Nacional de Tucumán, Tafí del Valle. Tucumán. 2003:1001- 1017. Tomo II.

INDEC. Censo Nacional Agropecuario 2002.

INDEC. Censo Nacional de Población y Vivienda. 2001

----La biotecnología y el modelo rural en los orígenes de la catástrofe que arrasa a la Argentina" Grupo de Reflexión Rural En Internet: http://www32.brinkster.com

---El capitalismo llegó al campo. En Revista Mercado. (1998: 22)

---El precio internacional del algodón no detiene su caída. Suplemento Norte Rural. En Diario Norte. 07/11/2001. P: 4.

---Historia de un productor algodonero al que siempre le fueron bien las cosas. Suplemento Norte Rural. En: Diario Norte. 06/09/2000. P.7

DONELLY, Lorenzo. La rentabilidad del algodón según el perfil del productor Suplemento Norte Rural. En: Diario Norte.02/01/2003. P.4.

LATTUADA, M y NEIMAN, G. El campo argentino, crecimiento con exclusión. Capital Intelectual. Buenos Aires. 2005

MANZANAL, Mabel. Los Programas de Desarrollo Rural en la Argentina (en el contexto del ajuste macroeconómico neoliberal). EURE v.26 n.78 Santiago set. 2000. http://www.scielo.cl/

NEIMAN, Guillermo (comp) El Trabajo de Campo. Producción, tecnología y empleo en el medio rural. Ed. Ciccus. Buenos Aires. 2001

OBSCHATKO, Edit. El peso económico de los pequeños productores agropecuarios. En: Desarrollo rural sostenible. COMUNIICA Ed. N66, II Etapa, abril- mayo, 2006.

PAZ, Raúl. Integración, exclusión y vulnerabilidad del campesino ocupante en Argentina. Estudios de caso en el marco de la globalización. En: Trabajo y Sociedad. Indagaciones sobre el empleo, la cultura y las prácticas políticas en sociedades segmentadas $N^{\circ}$ 2, vol. II, mayo-julio de 1999, Santiago del Estero, Argentina http://www.geocities.com/

PEÑA-MONTENEGRO, Raquel; QUIJANDRÍA, B. y MONARES, A.. Hacia una región sin pobres rurales. FIDA -.2001 http://www.ifad.org/ '

ROFMAN, Alejandro. Desarrollo regional y exclusión social. Transformaciones y crisis de la Argentina contemporánea. Amorrortu Editores. Buenos Aires. 2000

ROFMAN, Alejandro. Economías regionales. Modernización productiva y exclusión social en las economías regionales. En: Revista Realidad Económica No 162. Buenos Aires, IADE,1999

VALENZUELA, Cristina. Transformaciones agrarias y desarrollo regional. Bs. As. La Colmena, 2006

Publicado en formato digital: Prof. Alejandra $\mathrm{H}$. Torre Geraldi. POBREZA RURAL EN LA PROVINCIA DEL CHACO. UN ANÁLISIS A PARTIR DEL INDICE DE PRIVACIÓN MATERIAL DE LOS HOGARES (IPMH). Revista Geográfica Digital. IGUNNE. Facultad de Humanidades. UNNE. Año 9. No 17. Enero - Junio 2012. ISSN 16685180 Resistencia, Chaco. En: http://hum.unne.edu.ar/revistas/geoweb/default.htm 